\title{
Deductive Models of Policy Implementation and their Impact on Policy Outcome: A Critical Assessment
}

\author{
Hamidou Issaka Diori \\ The Graduate School of Public Administration (GSPA), National Institute of Development \\ Administration (NIDA), Bangkok 10240, Thailand
}

${ }^{*}$ Corresponding author email: hamidou.iss@stu.nida.ac.th

Received: 15 July 2021 / Revised: 10 September 2021 / Accepted: 12 September 2021 / Published: 26 September 2021

\begin{abstract}
Deductive models of policy implementation emerged as a response to the inability of inductive approaches to provide nuanced theories of policy implementation and performance. They are said to be parsimonious and precise in studying complex social interactions. Hence, over the last decade or so, there has been ascending interest in the use of deductive approaches to get deeper understanding of the mechanisms by which policy implementation is more likely to succeed. However, giving the fact that numerous programs and policies continue to fail despite being replicated from the best deductive models, one is entitled to wonder: what is the true value of these models? And how effective are they in translating the intentions of policymakers into desired policy outcomes? The present contribution seeks to provide answers to these questions by first, discussing some hands-on deductive models of policy implementation and second, analyzing the potential of each model, their strengths, their weaknesses, and appropriate contexts for use. To reach these aims, the study utilized the Contextual Interaction Theory (CIT) to gauge the assumptions of each of the following models: the Rational, Management, Organizational Development, Political, and Bureaucratic Process. The results have shown that, although deductive models of policy implementation (or at least, the models here-in discussed) seem to offer tangible promises to deliver more accurate and nuanced explanations of policy action, they fall short to combine the three criteria of Motivation, Information, and Power, necessary for any candidate model of policy implementation to be deemed effective. The results have also shown that an integrated model, one that combines the strengths of all the above cited models, but none of their weaknesses, could be a credible offer of a successful theory of policy implementation.
\end{abstract}

Keywords: Deductive Model; Policy Implementation; Implementation Outcome

\section{Introduction}

The word implementation means different things to different scholars depending on their own perspectives and policy realms. According to Pressman and Wildavsky (1973, pXiii) for instance, to implement a policy is to "carry it out, to accomplish, fulfill, produce, or complete the policy". Other definitions of the word implementation stressed a number of concepts ranging from "process", "interaction", "adoption", "management", or "complexity of joint action", to "task realization". In the context of this study, policy implementation is defined as the delivery of any policy plan or action (Burke et al., 2012). It is a complex, technical, and highly interactive process which does oftentimes call for consensus-building (Mthethwa, 2012).

Lots of policies failed in the past without adequate explanation. Today, we know more about the reasons thanks to the development of the study of policy implementation and the exerted effort of some scholars eager to identify factors along the way which may be responsible for failure or success in policy accomplishment (Saetren, 2014; Winter, 2012). However, the aforementioned development has brought not only clarity about the causes of policy failure, but also some controversies with regard to the best or 
say, appropriate strategies for effective policy implementations. Inductive theorists were first to look into the issue of policy performance. Yet, their accounts of implementation strategies and execution were assailed and rejected by their deductive counterparts on grounds that they were marred with radical perspectives, vagueness and lack of parsimony (Bressers et al., 2000). Looking into these controversies and anxious to contribute to the development of the field, Khan and Khandaker (2016) have proposed five deductive models of policy implementation. These models and the variables utilized are consistent with the existing literature and the lists of variables generated by scholars from both fields of policy implementation (implementation study and implementation science) and which were said to be critical for successful accomplishment of a policy plan or the explanation of its outcome (Domitrovich et al., 2008; Durlak \& DuPre, 2008; Wandersman et al., 2008; Fixsen et al., 2009; Meyers et al., 2012; Signé, 2017). Using the Contextual Interaction Theory, the present contribution seeks to determine the true value of the over extolled deductive approaches, by analyzing the models proposed by Khan and Khandaker (2016), assessing their strengths and weaknesses as well as their impact on policy outcome. The results are meant to show to the broader family of policy dons how deductive models fit within emerging developments as far as implementation is concerned. The results are also meant to provide the field with plausible candidate theories and approaches for sound policy implementation. The remainder of this assessment is organized as followed: section 2 proffers a succinct overview of deductive models of policy implementation and some of their overt limitations. Section 3 lays out a theoretical frame for the analysis of the models. Section 4 critically analyzes the most prominent models of deductive policy implementation using the contextual interaction theory (CIT). Section 5 proposes an integrated model, a centrist and more realistic account of successful policy implementation. And section 6 culminates the study with an interpretation of the findings and some policy implications.

\section{Deductive Models of Policy Implementation}

Deductive models of policy implementation often derive from economics (Owens, 2008). They emerged as a response to the inability of inductive approaches to provide acceptable nuanced theories of policy implementation and performance. They are mostly top-down approaches of policy implementation in that they are associated with excessive guidance and regulations, and tend to achieve the institution's goal rather than meeting local needs and concerns (Diori, 2021; Hudson et al., 2019; Mthethwa, 2012).

Deductive models of policy implementation are said to be parsimonious and more precise in studying complex social interactions. However, like their inductive counterparts, deductive models also seem to present some important strengths and limitations. Very often said some critics, they appear too sophisticated, especially for models that evolve from the economics literature. And in some cases, they deal carefully with the complex character of decision making, by relying on objectively-rational assumptions which sometimes even calculate the pros and cons on the basis of lucrative gain. Another potential limitation of most deductive models is based on the presumption that the policy will be implemented as decided upon, a point that is contradicted by a mass of existing research findings (Mthethwa, 2012). Finally, deductive models of policy implementation seem to focus implicitly on a one-actor decision-making. Again, this does not mean that all deductive approaches are top-down-models, but rather, that the implementer owns the final word even when other stakeholders are consulted.

\section{Framework of Analysis}

This study drew on the theory of Contextual Interaction developed in the Netherlands in the early 1980s. Parsimonious and realistic, the contextual interaction theory (CIT) was built to explicate the vital interaction between actors in the policy implementation process. It distills a great deal of implementation variables into three core constructs: the Motivation, Information, and Power of actors which had been identified as the key factors that have the greatest impact on implementation outcome (Owens, 2008). While motivation is said to impel actors, and can be seen in their readiness or not to participate; information is defined as the degree to which an organization is: (a) consensually clear about its tasks; (b) integrated by information 
Hamidou Issaka Diori, Adv. J Social Sci.; Vol. 9, Issue 1, pp: 1-9, 2021

exchanges; (c.) has clear knowledge about its performance (Owens, 2008). Power, the third variable guarantees actors a greater influence on policy implementation, and depends on the resources they own (Bressers et al., 2016; Owens and Bressers, 2013).

It should also be noted that the theory of contextual interaction rests on three main premises. First, it assumes that the mechanisms and results of a policy process are not solely a product of inputs, that they also depend fundamentally on actors' information, motivation, and power (Owens, 2008). Second, the theory presumes that policy implementation encompasses the completion of implementation per se, implementation avoidance, and some endeavors to change the goals of a given policy implementation. Third, the contextual interaction theory assumes that "the actors in a given interaction are likely to work together (or at least, have a history of working together) on other issues" (Owens, 2008, p.51). The variables of information, motivation, and power are not randomly chosen as the three most valuable ones, they are central to every interaction process and enjoy high explanatory power as far as the process dynamic is concerned (Owens, 2008). That is exactly the reason why the contextual interaction theory is chosen as theoretical lens in this study.

\section{Critical Analysis of the Models}

This section is concerned with the analytical aspect of the present study. Five deductive models of policy implementation are critically examined and their strengths and weaknesses exposed. These models which are the rational, management, organizational development, political, and bureaucratic process are believed to offer precise and more nuanced explanations of policy implementation.

\subsection{The Rational Model}

The rational model stresses the important of planning as medium for sound policy implementations (Diagram 1). It is a top-down approach to policy implementation which assumes that clarity of goals and objectives, accurate and consistent planning, clear and detailed task assignments, accurate standardization, and proper monitoring are essential for successful policy implementations (Khan \& Khandaker, 2016). Using the contextual interaction theory to test the soundness of the rational model, we found some significant assets and weaknesses with it. As far as "information" is concerned, information being the first implementation variable of the contextual interaction theory, and a prerequisite of sound policy implementation, the rational model appears advantageous. It provides clear and concise policy goals and objectives, and sets clear standards that are known to all actors. Hence, the model appears to fulfill the information criterion. But critics argue that a rational approach of any kind requires bulks of information that human intellect cannot provide.

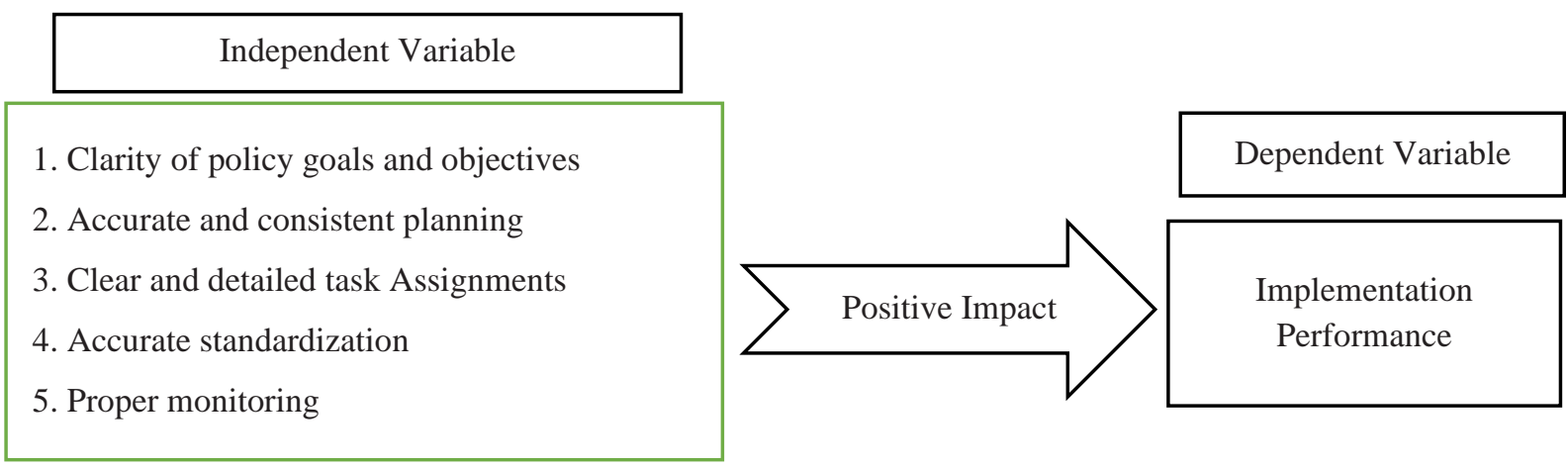

Diagram 1: variables involved in the Rational Model [Adopted with permission from Khan and Khandaker (2016)]

With regards to "motivation", the second variable of the contextual interaction theory, and measure of sound model, it incites actors, and ignites their readiness to participate. The rational model offers no clear indication of how motivation is supposed to be achieved. In this case, actors' motivation can only emanate 
from the highly organized and conducive nature of the work environment which sometimes are not enough in translating the intentions of policymakers into desired policy outcomes. In health care policy implementation for instance, Oh et al., (2021) have shown that the potential impact of a policy to advance health equity does not only depend on its design and implementation, but also on continuing evaluation and stakeholders' engagement. In other words, this insinuates that the process through which a policy is implemented determines how successfully each stage can deliver effective services.

Another drawback of the rational model is that it ignores human aspect as it says little about the program participants whose behavior they try to control through the use of "proper monitoring". Finally, the application of the rational model to the variable of "power" shows that it gives the implementer greater influence on the policy process. However, being a one-actor decision-making model where the implementer owns the final word even when other stakeholders are consulted, the rational model of policy implementation cannot be utilized in every policy setting.

\subsection{The Management Model}

The management model of policy implementation is a structure and resource-centered model (Diagram 2). It is premised upon the assumptions according to which good structure, clear and two-way communication, good utilization of personnel, good management of financial resources, and a good use of technology and location facilities produce sound policy implementation (Khan \& Khandaker, 2016). Are these assumptions valid?

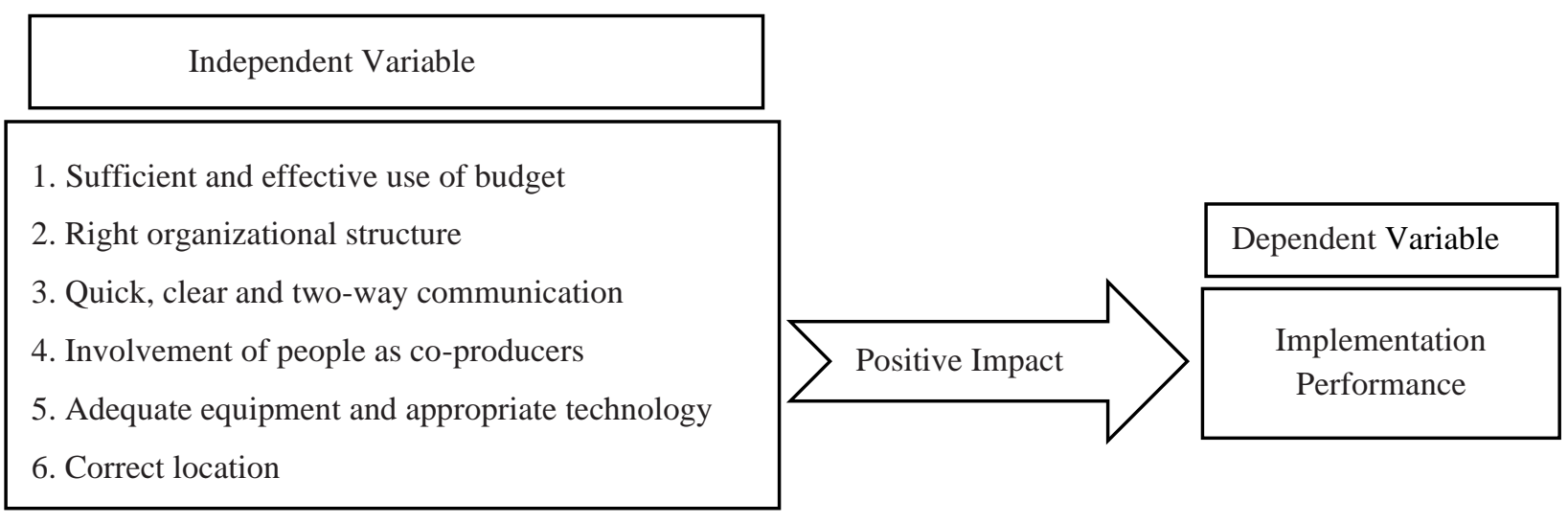

Diagram 2: variables involved in the Management Model

[Adopted with permission from Khan and Khandaker (2016)]

Viewed through our theoretical lens, and in accordance with its three variables that measure the soundness of an implementation model, the management model presents some tangible signs of strength and weaknesses. Our analysis revealed that, even though technology is used in this particular model, and that the actors may have clear knowledge about their performance, the management model does not make of "information" a key condition in carrying out a policy or program. That might be the reasons why the model focuses more on the organizational dynamic rather than clarifying the policy goals and objectives. Worse, little is said about the mission and assignments which normally ought to be known and agreed upon by all actors.

As for the motivation variable, the management model might be better responsive to change, but individual actors perform well when they are well informed and when they know more about their duties and the expectations that rest on their shoulders. The only way the model can ignite actors' motivation may come from its "two-way communication" or "the involvement of people as co-producers".

However, as far as the variable of power is concerned, the management model provides strong leadership through proper management of both human and financial resources. Despite the lack of clear information and mission, a policy may still be well accomplished if it is well thought of, well designed and above all, well conducted. 


\subsection{The Organizational Development Model}

The organizational development model is a bottom-up approach to policy implementation (Diagram 3). It rests on the assumptions according to which good leadership, accuracy of decision, high people's engagement and motivation, and finally a team and culture development are the key tools for a sound implementation performance (Khan \& Khandaker, 2016). This behavioral human-centered model views implementation as harmony: the more congruence there is between policy participants, the higher the chances of implementation success.

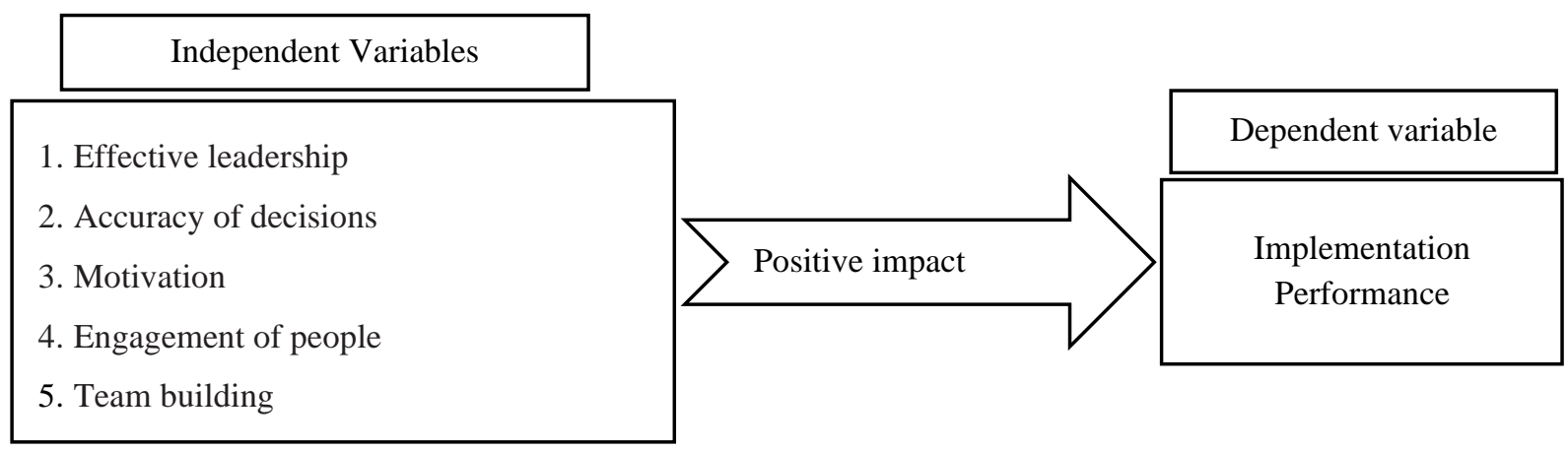

Diagram 3: variables involved in the Organizational Development Model [Adopted with permission from Khan and Khandaker (2016)]

Looking into this model, we can see that the only criteria left to fulfill the conditions of the contextual interaction theory is "information". That pertains to the clarification of the policy goals and objectives, the clarification of individual actors' tasks and accountability which normally lead to clearer understanding of the implementation performance. As for "motivation" and "power", the organizational model provides clear indications as for how they shape into its conception of implementation theory.

\subsection{The Political Model}

The political model accepts some degree of politics, the management of which it considers as a key step in policy implementation (Diagram 4). Broadly speaking, this model rests on the assumptions according to which complexity of joint actions and bureaucracy are not obstacles for a good policy outcome if participants can work to minimize the influence of pressure politics, resort to negotiation and work in harmony (Khan \& Khandaker, 2016). The fact that it is possible to bargain the outcome of a policy course allows the proponents of this model to be less skeptical over the issue of conflicts, bureaucracy and other delay causing factors.

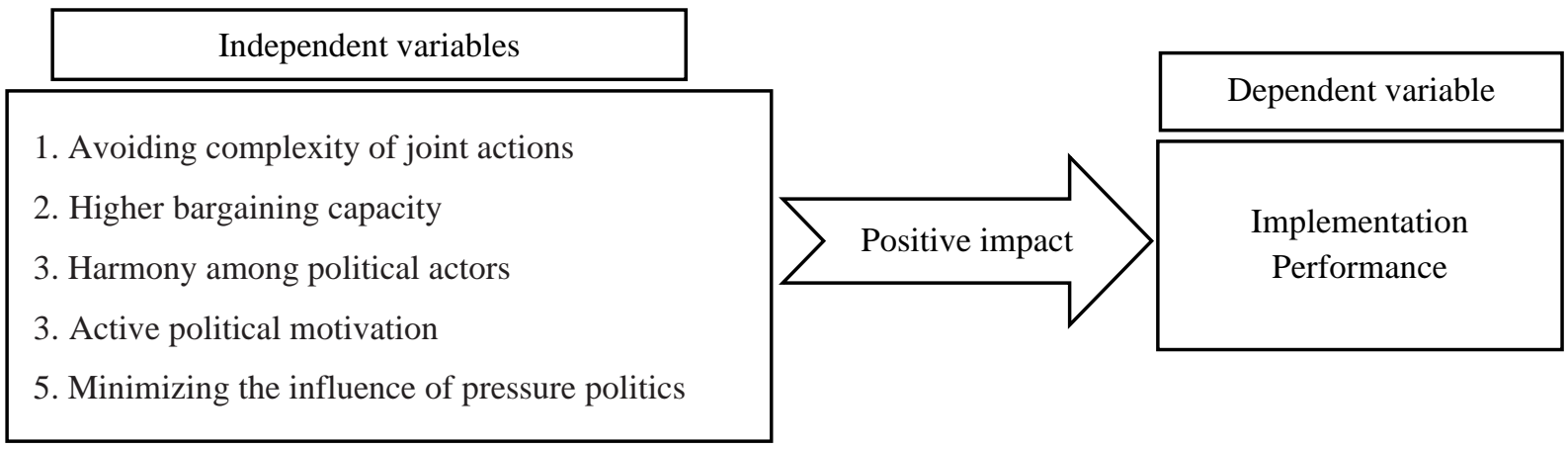

Diagram 4: variables involved in the Political Model [Adopted with permission from Khan and Khandaker (2016)]

When applied to the contextual interaction theory, this model showed some considerable strengths and limitations. While it says nothing about the policy mission, the goals and objectives, or a clear understanding of individual tasks and responsibilities, the political model could lead to further troubles in the 
implementation course. For, lack of information does not favor a policy setting where complexity of joint action already prevails.

As for the criteria of motivation and power, the former is difficult to ensure in a situation of administrative dilemma and conflict. In fact, too much bureaucracy and administrative control can only dissipate participants' energy. However, if efforts are made to circumvent complexity of joint action and minimize pressure politics, the model might yield some active political motivation. This is also true for "power", which might be obtained thanks to the high bargaining capacity and the harmony that the model can install among political actors.

\subsection{The Bureaucratic Process Model}

The bureaucratic process model, also called "implementation as compliance" reveals the phenomenal reality of policy implementation (Diagram 5). It emphasizes the role of the front-line implementer upon whom the success of a policy course depends. This model assumes that top hierarchy's understanding ability, the discretion and commitment of front-line staff members determine the outcome of a policy (Khan \& Khandaker, 2016). Critically examined, the model was found with certain edge concerning the criterion of "power". In empowering the front-line actors to make decisions, this model confers them a greater influence over the policy implementation. However, this kind of button-up decision making may complicate strategic situations. One actor or group of actors may want to play the "hierarchical game" and decide to go by the book. To circumvent this kind of scenario, high level of compliance and commitment are required.

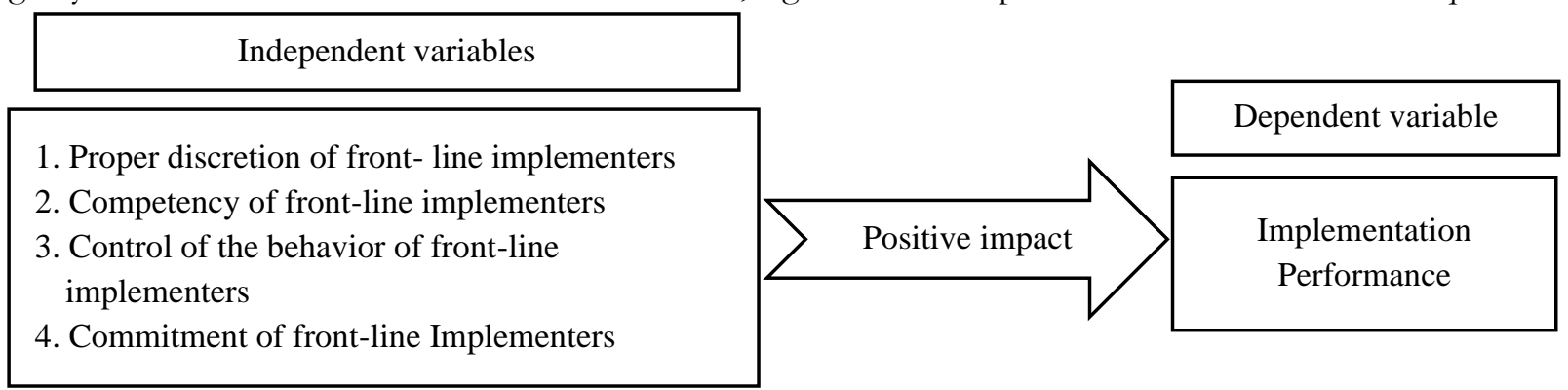

\section{Diagram 5: variables involved in the Bureaucratic Process Model [Adopted with permission from Khan and Khandaker (2016)]}

Regarding the variable of "information", the bureaucratic model says nothing about clarity of tasks, information exchanges, or having clear knowledge about the implementation performance. Yet, since the model relies on the discretion and the competence of front-line implementers and that discretion can improve actors' behavior, it is possible that harmony prevails, and information well disseminated.

Lastly, in empowering the front-line implementers, there is great chance to meet the criterion of motivation. The role inversion (button-up rather than top-down) may result in a boost of motivation and commitment on the part of front-line implementers.

\section{Model Integration}

The deductive models discussed in the previous section, present - all of them - a design drawbacks upon close inspection. The rational model seems to satisfy two of the three criteria of our conceptual framework: information and power, but fails short to comply with the motivation criterion. The management model fails to satisfy the criteria of information and motivation, but proves itself powerful in guaranteeing the implementer a greater influence over the policy process and outcome. The organizational development model misses only the criterion of information to be a complete and effective model of policy implementation. The political model is flawed concerning the information criterion, but could induce motivation and power if the program participants can "minimize the influence of pressure politics" and or avoid the recurrent problem of "joint action complexity". And lastly, the bureaucratic process model, satisfies only the criterion of power which itself looks ephemeral as it can shift from side to side at any 
Hamidou Issaka Diori, Adv. J Social Sci.; Vol. 9, Issue 1, pp: 1-9, 2021

point in time throughout the policy process. For all these reasons, we aimed for a general deductive approach that has the potential to explain policy implementation process and capture the strengths of all the five above mentioned models but none of their disadvantages.

\subsection{The Integrated Model}

This integrated model (Diagram 6) encompasses effective leadership from the organizational development model; clarity of goals and objectives, clarity and detailed task assignment from the rational model; right organizational structure and effective use of resources from the management model; and commitment of front-line implementers from the bureaucratic process model. The assumptions of this integration and the chosen variables are all represented in the following design and discussed in the subsequent section.

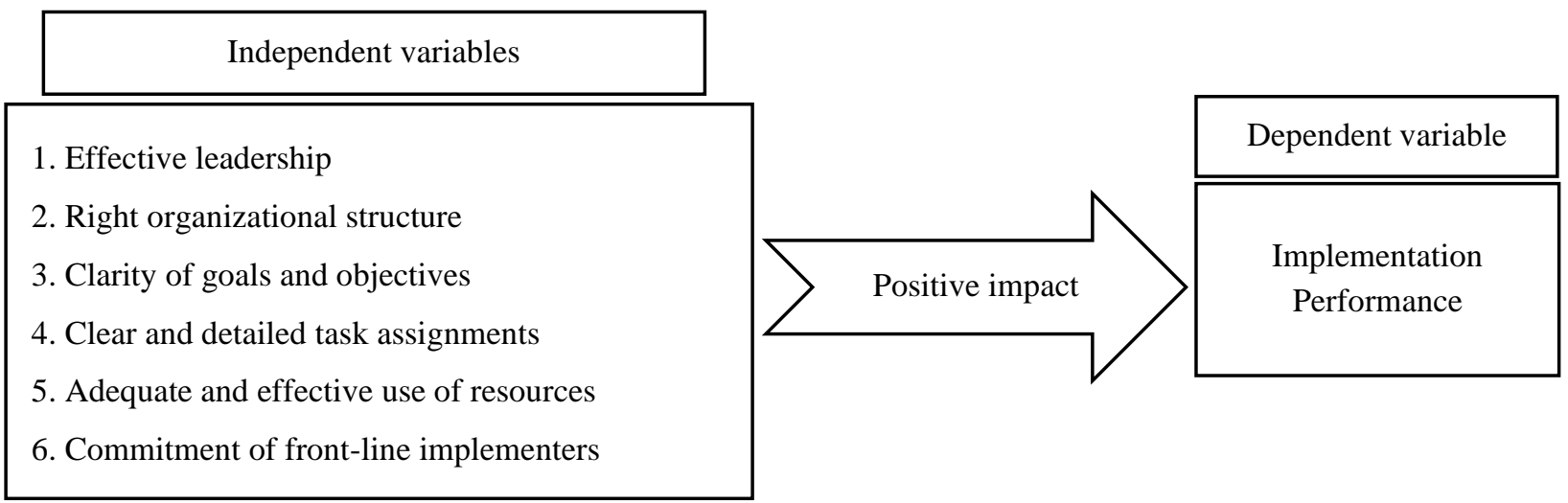

Diagram 6: variables involved in the Integrated Model

\subsection{Justification of the Integrated Model and Choice of Variables}

Key components of the integrated model, the following variables are chosen for their obvious impact on a policy outcome:

- Effective Leadership: leadership is the prime factor that determines a policy outcome. It is the first variable of the integrated model because it clearly satisfies the criterion of "power" around which all the other variables gravitate. Effective leaders are essential to the success of every policy or program. They are upfront individuals with positive attitude who motivate their subordinates to work best and hold them accountable when they don't. Good leaders also unite their teams around a single vision. Their main duty here is to oversee, to protect, to follow up, to overhaul, correct, and expand the policy process. In the words of Bardach, the leader's job is to fix the various implementation games (1980). A good leader should thus be able to handle the numerous bureaucratic and political games the most common form of which is the dilemma of administration (tokenism, massive resistance, social entropy and management game).

- Right organization structure: effective leaders use good organizational structures to effectively manage both the implementation process and the organizational resources. Having the right organizational structure helps to streamline the implementation activities, improve decision-making, and personnel performance. It also helps motivate policy participants since it creates a conducive work environment and harmony among the political actors throughout the policy execution.

- Clarity of goals and objectives: clarifying policy goals and objectives helps to articulate the program's orientation and the nature of the service needs. It also helps build common understanding and consensus among staff members and other stakeholders about essential policy activities and expected outcomes. It is worthwhile recalling here that a policy implementation process is one of strategic interaction among several special interests all following their own goals which may or may not be compatible with the goal of the policy mandate (Bardach, 1980). Thus, in clarifying its goals and objectives, a policy course might be protected from the risk of goals and paths dichotomy or the emergence of unexpected decisions that may cause serious delay in the program execution. 
- Clear and detailed task assignments: detailing and clarifying tasks or assigning missions and establishing accountability help keep policy actors focused and devoted to their tasks. Clear tasks, mission, or responsibility assignments; and clear policy goals and objectives are part of the variable of "information", another key implementation factor needed for any candidate model to be effective. Once a model fulfills this criterion, actors' engagement and motivation as separate variables are no longer to be forced because good leadership and information are more than enough to drive enthusiasm, commitment and willingness of actors to perform well. Good leaders don't have to exercise much control or reward their staffers to carry out their assigned tasks.

- Adequate and effective use of resources: by resources, we mean the whole of all human, financial, and material aspects that can be put in place in the accomplishment of a policy mandate. A good structure and resources management necessarily leads to good performance and ignites actors' motivation. Here again the integrated model meets the criterion of "motivation", the third implementation variable of our theoretical framework. Effective leadership, good organizational structure, adequate and effective use of resources and clear goals and tasks assignments can stimulate both staff members and other policy participants.

- Commitment of front-line implementers: though the integrated model is cogent as far as "power" and "information" are concerned, the commitment of front-line implementers is needed for a successful policy implementation. Engagement or say, commitment of front-line actors is caused by top hierarchical understanding-ability which itself usually comes from good leadership. Good leaders delegate power to their most trusted front-line subordinates so as to control their behavior and get them more involved in the task realization.

\section{Conclusion}

This contribution confirmed the claim that deductive approaches are a promising way to developing implementation theories despite the fact that none of the analyzed models has met the three criteria of the theoretical test. The main implication here is to consider the use of an integrated model, one that combines the strength of all of the rational, management, organizational development process, political, bureaucratic process models, but none of their weaknesses. Such a model has the potential to be a more nuanced, more effective, and complete theory of policy implementation. While a good leader inspires his or her associates, gets the needed resources and effectively utilized them; the detailed and clear policy goals and objectives they spell out could stir staff members readiness to fully participate. And once the missions and individual tasks are well assigned, and responsibilities established, the whole organization will be integrated by information exchanges. Information, motivation, and effective resource management give actors a greater influence (power) upon policy actions.

\section{Competing Interests}

The author declared that no conflict of interest exists in this publication.

\section{How to Cite this Article:}

Diori, H. I. (2021). Deductive Models of Policy Implementation and their Impact on Policy Outcome: A Critical Assessment. Advanced Journal of Social Science, 9 (1), 1-9. https://doi.org/10.21467/ajss.9.1.1-9

\section{References}

Bardach, E. (1980). The Implementation Game: What Happens After a Bill Becomes a Law. The MIT Press.

Bressers, N., Bressers, J. T. A., \& Larrue, C. (2016). Introduction 'Governance for Drought Resilience'. In H. Bressers, N. B ressers, \& C. Larrue (Eds.), Governance for Drought Resilience: Land and Water Drought Management in Europe (pp. 1-16). Springer. https://doi.org/10.1007/978-3-319-29671-5_1.

Bressers, J. T. A., Klok, P. J., \& O'Toole, L. J. (2000). Explaining policy action: A deductive but realistic theory. Paper presented at the IPSA World Congress, Quebec, 2000.

Burke, K., Morris, K., \& McGarrigle, L. (2012). An Introductory Guide to Implementation: Terms, Concepts and Frameworks. Centre for Effective Services. 
Hamidou Issaka Diori, Adv. J Social Sci.; Vol. 9, Issue 1, pp: 1-9, 2021

Diori, H. I. (2021). A Critical Insight into Needs Assessment Technique and the Way Social Needs are Actually Assessed. Advanced Journal of Social Science, 8 (1), 3-9. https://doi.org/10.21467/ajss.8.1.3-9

Domitrovich, C. E., Bradshaw, C. P., Poduska, J. M., Hoagwood, K., Buckley, J. A., Olin, S., Romanelli, L. H., Leaf, P. J., Greenberg, M. T., \& Ialongo, N. S. (2008). Maximizing the Implementation Quality of Evidence-Based Preventive Interventions in Schools: A Conceptual Framework. Advances in School Mental Health Promotion, 1(3), 6-28.

Durlak, J. A., \& DuPre, E. P. (2008). Implementation Matters: A Review of Research on the Influence of Implementation on Prog ram Outcomes and the Factors Affecting Implementation. American Journal of Community Psychology, 41(3-4), 327-50.

Fixsen, D. L., Blase, K. A., Naoom, S. F., \& Wallace, F. (2009). Core Implementation Components. Research on Social Work Practice, 19 (5), 531- 540.

Hudson, B., Hunter, D., \& Peckham, S. (2019). Policy failure and the policy-implementation gap: can policy support programs help? Policy Design and Practice, 2(1), 1-14.

Khan, A. R., \& Khandaker, S. (2016). A Critical Insight into Policy Implementation and Implementation Performance. Public Policy and Administration, 15(4), 538-548.

Meyers, D. C., Durlak, J. A., \& Wandersman, A. (2012). The Quality Implementation Framework: A Synthesis of Critical Steps in the Implementation Process. American Journal of Community Psychology, 50(3-4), 462-80.

Mthethwa, R. M. (2012). Critical dimensions for policy implementation. African Journal of Public Affairs, 5(2), 36-47.

Oh, A., Abazeed, A., \& Chambers, D.A. (2021). Policy Implementation Science to Advance Population Health: The Potential for Learning Health Policy Systems. Front. Public Health, 9:681602. https://doi.org/10.3389/fpubh.2021.681602.

Owens, K. A., \& Bressers, J. T. A. (2013). A Comparative Analysis of How Actors Implement: Testing the Contextual Interaction Theory in 48 Cases of Wetland Restoration. Journal of comparative policy analysis, 15(3), 203-219.

Owens, K. A. (2008). Understanding how actors influence policy implementation: a comparative study of wetland restorations in New Jersey, Oregon, the Netherlands and Finland. Enschede: University of Twente.

Pressman, J. L., \& Wildawsky, A. (1973). Implementation ( $2^{\text {nd }}$ edition). University of California Press.

Seatren, H. (2014). Implementing the Third Generation Research Paradigm in Policy Implementation Research: An Empirical Assessment. Public Policy and Administration. https://doi:10.1177/0952076713513487.

Signé, L. (2017). Policy Implementation: A synthesis of the Study of Policy Implementation and the Causes of Policy Failure. Research papers $\&$ Policy papers, 1703. Policy Center for the New South.

Wandersman, A., Duffy, J., Flaspohler, P., Noonan, R., Lubell, K., Stillman, L., Blachman, M., Dunville, R., \& Saul, S. (2008). Bridging the Gap Between Prevention Research and Practice: The Interactive Systems Framework for Dissemination and Implementation. American Journal of Community Psychology, 41(3-4),171-81.

Winter, S. C. (2012). Implementation perspectives: status and reconsideration. In B. G. Peters, \& J. Pierre (Eds.), The SAGE handbook of public administration (pp. 265-278). SAGE Publications Ltd, https://www.doi.org/10.4135/9781446200506.n17.

\section{Publish your research article in AIJR journals- Online Submission and Tracking \\ Peer-Reviewed \\ Rapid decision \\ Immediate Publication after acceptance \\ Articles freely available online \\ Retain full copyright of your article.}

Submit your article at journals.aijr.org
Publish your books with AIJR publisher-

Publish with ISBN and DOI.

$\checkmark \quad$ Publish Thesis/Dissertation as Monograph.

$\checkmark \quad$ Publish Book Monograph.

$\checkmark \quad$ Publish Edited Volume/ Book.

$\checkmark \quad$ Publish Conference Proceedings

$\checkmark \quad$ Retain full copyright of your books.

Submit your manuscript at books.aijr.org 